\title{
Oral Anticoagulation: the impact of the therapy in health-related quality of life at six-month follow-up ${ }^{1}$
}

\author{
Ariana Rodrigues da Silva Carvalho ${ }^{2}$ \\ Márcia Aparecida Ciol ${ }^{3}$ \\ Felice Tiu ${ }^{4}$ \\ Lídia Aparecida Rossi ${ }^{5}$ \\ Rosana Aparecida Spadoti Dantas ${ }^{6}$
}

\begin{abstract}
Objective: to study the changes in health-related quality of life from beginning of anticoagulation therapy to six-month follow-up, and to study associations of sociodemographic and clinical characteristics with measures of quality of life and general health status at six-month followup, in individuals using oral anticoagulation due to various medical indications for the therapy. Method: prospective study performed at a city in the state of Paraná, Brazil, composed of 78 patients. Measures included the Duke Anticoagulation Satisfaction Scale and the Medical Outcomes Survey Short Form SF-36. Results: mean age was 57 years (S.D.=16) and 54\% were women. Compared to the beginning of therapy, there was a statistically significant improvement in health-related quality of life at six-month follow-up. Linear regression analyses explained $32 \%$ and $30 \%$, respectively, of the variance of the Duke Anticoagulation Satisfaction Scale and of the general health status. There was improvement in all components of the SF-36, except Mental Health. Conclusion: The use of oral anticoagulation therapy was associated with improvement in health-related quality of life in the first six months of therapy. This study is longitudinal and therefore, has fewer limitations than cross-sectional studies published to date in the Nursing literature in Brazil.
\end{abstract}

Descriptors: Anticoagulants; Quality of Life; Clinical Evolution; Nursing.

\footnotetext{
1 Paper extracted from Doctoral Dissertation "Qualidade de vida relacionada à saúde e adesão ao tratamento de indivíduos em uso de anticoagulação oral: avaliação dos seis primeiros meses de tratamento" presented to Escola de Enfermagem de Ribeirão Preto, Universidade de São Paulo, WHO Collaborating Centre for Nursing Research Development, SP, Brazil.

2 PhD, Assistant Professor, Universidade Estadual do Oeste do Paraná, Brazil.

${ }^{3} \mathrm{PhD}$, Research Associate Professor, School of Medicine, University of Washington, USA.

${ }^{4}$ MSc, Mathemathics \& Statistics Faculty, Seattle Central Community College, USA.

5 PhD, Professor, Escola de Enfermagem de Ribeirão Preto, Universidade de São Paulo, WHO Collaborating Centre for Nursing Research Development, Brazil.

${ }^{6}$ PhD, Associate Professor, Escola de Enfermagem de Ribeirão Preto, Universidade de São Paulo, WHO Collaborating Centre for Nursing Research Development, Brazil.
} 


\title{
Anticoagulação oral: impacto da terapia na qualidade de vida relacionada à saúde ao longo de seis meses
}

Objetivo: estudar as mudanças na qualidade de vida relacionada à saúde do início da anticoagulação oral ao final de seis meses dessa terapia, e estudar as associações das características sociodemográficas e clínicas com as medidas de qualidade de vida e estado de saúde geral seis meses após o início do tratamento, em indivíduos com diversas indicações clínicas para anticoagulação oral. Método: estudo prospectivo realizado em um município do Paraná, Brasil, avaliando 78 pacientes. Foram utilizados os instrumentos Duke Anticoagulation Satisfaction Scale e Medical Outcomes Survey Short Form SF-36. Resultados: a idade média foi 57 anos (D.P. $=16$ ) e 54\% eram mulheres. Comparado com o início da terapia, houve melhora estatisticamente significante na qualidade de vida relacionada à saúde aos seis meses de seguimento. Os modelos de regressão linear explicaram $32 \%$ e $30 \%$, respectivamente, da variância do Duke Anticoagulation Satisfaction Scale e do estado geral de saúde. Houve melhora em todos os componentes do SF-36, exceto Saúde Mental. Conclusão: O uso do anticoagulante oral foi associado à melhora da qualidade de vida relacionada à saúde nos seis meses de acompanhamento. Por ser longitudinal, esse estudo tem menos limitações que os estudos transversais publicados na área da Enfermagem brasileira até o momento.

Descritores: Anticoagulantes; Qualidade de Vida; Evolução Clínica; Enfermagem.

\section{Anticoagulación oral: impacto de la terapia en la calidad de vida relacionada a la salud a lo largo de seis meses}

\begin{abstract}
Objetivo: Estudiar los cambios en la calidad de vida relacionada con la salud desde el inicio de la anticoagulación oral y al final de seis meses de tratamiento, y estudiar las asociaciones de las características sociodemográficas y clínicas con las medidas de calidad de vida y salud general seis meses después de iniciar la terapia, en pacientes con diversas indicaciones clínicas de anticoagulación oral. Método: Se realizó un estudio prospectivo en una ciudad de Paraná, Brasil, evaluando 78 pacientes. Las herramientas aplicadas fueron la Duke Anticoagulation Satisfaction Scale y el Medical Outcomes Survey Short Form SF-36. Resultados: La edad promedia fue de 57 años (D.E.=16) y el $54 \%$ era mujer. En comparación con el inicio de la terapia, se observó una mejoría estadísticamente significativa en la calidad de vida relacionada con la salud tras seis meses de seguimiento. El análisis de regresión representó el $32 \%$ y $30 \%$, respectivamente, de la varianza de la Duke Anticoagulation Satisfaction Scale y la salud general. Hubo una mejora en todos los componentes del SF-36, excepto la Salud Mental. Conclusión: El uso de anticoagulantes orales se asocia con una mejoría en la calidad de vida relacionada con la salud tras seis meses de seguimiento. Debido a su diseño longitudinal, este estudio trae menos limitaciones que los estudios transversales publicados en la Enfermería brasileña hasta ahora.
\end{abstract}

Descriptores: Anticoagulantes; Calidad de Vida; Evolución Clínica; Enfermería.

\section{Introduction}

Oral anticoagulation therapy (OAT) is widely used to prevent and manage thromboembolic events; however, often its usage is difficult due to the fluctuations of blood coagulation values which require a rigorous laboratorial follow-up, and consequently, causing an impact in the quality of life of the OAT users ${ }^{(1)}$. Studies have investigated various aspects of health-related quality of life (HRQoL) in OAT users, such as limitations due to medication use, hassle and burden, and psychological impact, both negative and positive ${ }^{(2)}$. A study was conducted in an academic hospital of the state of São Paulo to assess the association between HRQoL and various factors, which included duration of medicament use and presence of complications resulting from the therapy. In this longitudinal study, 178 participants were interviewed and HRQOL was assessed through the eight domains of the Medical Outcomes Survey Short Form (SF-36). The results indicated that women, older 
adults, with diagnosis of atrial fibrillation, and with less than one year of OAT presented a lower HRQoL (3).

In this study, we used the theoretical definition of HRQoL that focus on how much the disease or chronic condition, in addition to its symptoms, interfere in the person's daily life, that is, how much the affected person perceives the manifestations of the disease and its treatment ${ }^{(4)}$. In the clinical setting, the evaluation of the psychological impact, burden and limitations, and satisfaction with OAT might help to support interventions with the objective of increasing the adherence to OAT, and therefore, increasing the likelihood that the person is within the therapeutic levels and reducing the incidence of adverse events such as thromboembolism or hemorrhages ${ }^{(1)}$.

The participation of nursing professionals in clinics specialized in OAT is a practice still new in Brazil, although it has been often cited as practice in international studies. In the Nursing area in Brazil, recent research involving OAT patients have used cross-sectional designs ${ }^{(3,5-6)}$, limiting the conclusions regarding the studied factors. To address some of those limitations, the current study was designed to follow a sample of patients during the first six months of OAT.

The objectives of this work were: 1 ) to study the changes in HRQoL (evaluated by the eight components of the SF-36, the Duke Anticoagulation Satisfaction Scale [DASS], and perceived general health status) from the beginning of the treatment with oral anticoagulants to the end of six months of therapy, in a group of individuals initiating the treatment; 2) to study associations of sociodemographic and clinical characteristics (at baseline) with measures of DASS and general health status at six-month follow-up.

\section{Methods}

\section{Study design, location of study, and sample selection}

This study was a prospective and observational study conducted in public and private health service institutions of a city of the Western region of Paraná state, Brazil. The study was approved by the hospital's human subjects ethic committee and the study objectives were explained verbally and in written to all participants. Individuals who agreed to participate signed an informed consent prior to data collection. Inclusion criteria included individuals 18 years and older using OAT, who had initiated treatment no longer than two months prior to enrollment. This period is the average time needed to adjust the therapeutic dose of the medication, and it was used in a prospective cohort study of treatment adherence in the United States of America patients(7). Exclusion criteria included: individuals who were incapable to communicate verbally, who had previous diagnostic of mental diseases, or were not available to participate in both evaluations (baseline and six-month follow-up). The enrollment of participants occurred between April 2008 and June 2009.

\section{Data collection}

Data were collected through individual interviews and medical chart review in two moments: at baseline (within two months of initiation of OAT) and at six months of OAT. The following data were collected: sociodemographic (age, sex, and number of years of formal education) and clinical characteristics (number of medications beyond OAT, weekly dose and reason for prescription of OAT, information about the therapeutic interval of OAT, and presence of complications (yes/no) such as hemorrhagic episodes and/or thromboembolic events in the first six months of therapy). Clinical information was collected from medical charts, while other information, including HRQoL measures (described below), were collected through self-report.

\section{Measures of HRQoL}

The Medical Outcomes Survey 36-Item Short-Form $(\mathrm{SF}-36)^{(8)}$ was used in its Portuguese validated version ${ }^{(9)}$ to evaluate HRQoL in the four-week period prior to the interview. The SF-36 is composed of eight domains, each evaluated in a scale of 0 to 100 , with larger values indicating better HRQOL in the respective domain.

The evaluation of the current general health status (GHS) was obtained through the question "In general, how do you rate your health today?", which was answered using a visual analogue scale (VAS) of 10 $\mathrm{cm}$, anchored with the value 0 (worst health possible) on the left and 100 (best health possible) on the right. Higher values indicated better evaluation of the GHS, according to the participant's perception at the time of the interview ${ }^{(10)}$.

The evaluation of HRQoL specific for oral coagulant users was performed using the Duke Anticoagulation Satisfaction Scale (DASS) ${ }^{(2)}$ in its version validated for Brazil(11), and applied to the participants at six months after beginning OAT. The DASS measures the satisfaction with treatment and the OAT-related quality of life. The scale is composed of 25 items, each with a five-point ordinal scale, and the sum of the items defines the total DASS. Lower DASS scores indicate greater satisfaction 
with OAT use, fewer limitations, less burden, and less psychological impact of the medication.

\section{Statistical Analysis}

Descriptive analysis was performed for all variables. For objective 1, we compared the domains of SF-36, DASS, and GHS at baseline and six-month follow-up using the paired t-test. For objective 2, we performed linear regression analyses, using DASS and GHS at sixmonth follow-up as the response variables. Both models had the following explanatory variables: age (in years), sex, reason for prescription of OAT (mechanical valve prosthesis, atrial fibrillation, or deep vein thrombosis/ thromboembolism/other), number of comorbidities, and presence of complications related to the therapy during the first six month of treatment. Significance level was set to 0.05 . Due to exploratory nature of this research, the significance level was not adjusted for multiple comparisons. The results of this study should be interpreted as basis for future confirmatory studies. Data analysis was conducted using IBM SPSS (version 19.0 for Mac and 20.0 for Windows).

\section{Results}

Seventy-eight individuals participate in the study, with a mean age of 57 years (S.D.=16), 15\% with less than 40 years, $41 \%$ between 40 and 59 years, and $44 \%$ with 60 years or more. In the sample, $54 \%$ were females, $72 \%$ were married, $6 \%$ lived alone, and $65 \%$ had less than eight years of formal education. Average monthly family income was $\mathrm{R} \$ 1350$, but despite the low income, $97 \%$ of the participants paid the OAT treatment with their own resources. In the baseline interview, the mean time of OAT use was 23 days (S.D. $=9$, range: 5 to 46$)$, while in the second interview the average was 184 days (S.D. $=8$ ). Reasons for indication of OAT included atrial fibrillation (35\%), deep vein thrombosis or pulmonary thromboembolism or other $(38 \%)$, and use of mechanical valve prosthesis (27\%). Presence of comorbidities were common among the participants, with only $17 \%$ of them presenting no other morbidity than the one that indicated OAT. During the followup period, $19 \%$ of the participants had at least one complication related to OAT, all of which were of hemorrhagic type.

Results from HRQoL measures are presented in Table 1. There was improvement in all domains of the SF-36 ( $p<0.002$ for all domains), except for Mental Health $(p=0.42)$. The largest improvement occurred for Physical Aspects, followed by Emotional Aspects, Functional Capacity, and Pain. Smaller improvements were observed for Social Aspects, General Health and Vitality. There was a statistically significant improvement in GHS measured by the visual analogue scale at sixmonth follow-up when compared to baseline (change of 9 points, $p<0.001)$. The mean DASS at six-month follow-up was 45 (S.D. = 14, 95\% confidence interval $=[42,48])$, which represents a low impact of the OAT use perceived by the participants. Note that DASS is a measure of satisfaction and quality of life related to the use of OAT in individuals for whom the treatment is well-established, and therefore it was not applicable to the baseline interview.

Table 1 - Measures of health-related quality of life (HRQoL) of participants at baseline (within 2 months from beginning of treatment) and at six-month follow-up of treatment with OAT. Cascavel, PR, Brazil, 2008-2009

\begin{tabular}{|c|c|c|c|c|c|}
\hline \multirow[b]{2}{*}{ Measures of HRQoL } & \multicolumn{2}{|c|}{ Beginning of OAT treatment ${ }^{\star}$} & \multicolumn{2}{|c|}{ 6-month follow-up } & \multirow[b]{2}{*}{ p-value ${ }^{\dagger}$} \\
\hline & Mean (S.D.) & $\begin{array}{c}\text { Median } \\
\text { (Min.; Max.) }\end{array}$ & Mean (S.D.) & $\begin{array}{c}\text { Median } \\
\text { (Min.; Max.) }\end{array}$ & \\
\hline \multicolumn{6}{|l|}{ SF-36 Domains } \\
\hline Physical Aspects & $32(44)$ & $0(0 ; 100)$ & $73(43)$ & $100(0 ; 100)$ & $<0.001$ \\
\hline Emotional Aspects & $61(48)$ & $100(0 ; 100)$ & $90(31)$ & $100(0 ; 100)$ & $<0.001$ \\
\hline Functional Capacity & $70(24)$ & $77(15 ; 100)$ & $85(18)$ & $95(10 ; 100)$ & $<0.001$ \\
\hline Pain & $64(30)$ & $62(0 ; 100)$ & $83(21)$ & $92(21 ; 100)$ & $<0.001$ \\
\hline Social Aspects & $83(26)$ & $100(13 ; 100)$ & $91(17)$ & $100(38,100)$ & 0.01 \\
\hline General Health & $74(24)$ & $87(10 ; 100)$ & $81(20)$ & $92(5 ; 100)$ & 0.002 \\
\hline Vitality & $67(23)$ & $70(10 ; 100)$ & $72(18)$ & $75(20 ; 100)$ & 0.008 \\
\hline Mental Health & $72(20)$ & $76(24 ; 100)$ & $73(17)$ & $76(24 ; 100)$ & 0.41 \\
\hline General Health Status (GHS) & $74(22)$ & $73(11,100)$ & $83(18)$ & $85(27 ; 100)$ & $<0.001$ \\
\hline DASS & N.A. ${ }^{\ddagger}$ & N.A. ${ }^{\ddagger}$ & $45(14)$ & $41(26 ; 92)$ & \\
\hline
\end{tabular}

*OAT: Oral anticoagulation therapy; $+p$-value from paired t-test; $\neq \mathrm{NA}=$ Not applicable 
For the second objective, we performed two linear regression analyses using DASS and GHS at six-month follow-up as the response variables, and age, sex, reason for prescription of OAT, number of comorbidities, and presence of complications related to the therapy during the first six months as explanatory variables. GHS at baseline was also added to the linear regression for GHS at six months follow-up. Table 2 shows the results of the linear regression for DASS. Only number of comorbidities was statistically significant $(p=0.005)$, with individuals without other comorbidity and with 1 to 3 comorbidities presenting, on average, 17 and 4 points more in the DASS than individuals with 4 or more comorbidities. Participants without comorbidities other than the reason for OAT were less satisfied with the treatment impact in their lives than participants who had other diseases or conditions. Reason for prescription of OAT was nearly statistically significant $(p=0.06)$, with individuals in the atrial fibrillation and deep vein thrombosis/pulmonary thromboembolism presenting higher values of DASS than the group with mechanical valve prosthesis. The linear regression model explained $32 \%$ of the variance of DASS.

Table 2 - Linear regression for DASS six month after beginning of oral anticoagulation therapy (OAT). Cascavel, PR, Brazil, 2008-2009

\begin{tabular}{|c|c|c|c|}
\hline \multirow{2}{*}{ Explanatory Variables } & \multicolumn{2}{|c|}{ Coefficient } & \multirow{2}{*}{ p-value } \\
\hline & Estimative & Standard Error & \\
\hline Age (in years) & -0.19 & 0.12 & 0.12 \\
\hline Sex (Ref.: female) & -0.39 & 2.98 & 0.89 \\
\hline Reason for prescription of OAT (Ref.: mechanical valve prosthesis) & & & 0.06 \\
\hline Atrial Fibrillation & 6.99 & 4.23 & 0.10 \\
\hline $\mathrm{DVT}^{*}, \mathrm{PTE}^{\dagger}$ and others & 9.24 & 3.84 & 0.02 \\
\hline Comorbidities (Ref.: 4 or more) & & & 0.005 \\
\hline None & 17.13 & 5.11 & 0.001 \\
\hline 1 to 3 comorbidities & 4.25 & 3.30 & 0.20 \\
\hline Complications (Ref: 1 or more) & -4.68 & 3.71 & 0.21 \\
\hline
\end{tabular}

$\mathrm{R}^{2}=0.323 ;$ adjusted $\mathrm{R}^{2}=0.256$

* DVT - Deep Vein Thrombosis; TPTE - Pulmonary Thromboembolism

Table 3 shows the results of the linear regression for GHS at six-month follow-up. Only the GHS at baseline was statistically significant in the model $(p<0.001)$, with
$\mathrm{R}^{2}=0.303$ (or $30 \%$ of the variance explained by the model).

Table 3 - Linear regression for general health status (GHS) measured by a visual analogue scale (VAS) at six months after beginning of oral anticoagulation therapy (OAT). Cascavel, PR, Brazil, 2008-2009

\begin{tabular}{|c|c|c|c|}
\hline \multirow{2}{*}{ Explanatory Variables } & \multicolumn{2}{|c|}{ Coefficient } & \multirow{2}{*}{ p-value } \\
\hline & Estimative & Standard Error & \\
\hline Age (in years) & -0.04 & 0.15 & 0.79 \\
\hline Sex (Ref.: female) & 1.38 & 3.81 & 0.72 \\
\hline Reason for prescription of OAT (Ref.: mechanical valve prosthesis) & & & 0.54 \\
\hline Atrial Fibrillation & 1.07 & 5.39 & 0.84 \\
\hline $\mathrm{DVT}^{\star}, \mathrm{PTE}^{\dagger}$ and others & 4.93 & 4.90 & 0.32 \\
\hline Comorbidities (Ref.: 4 or more) & & & 0.58 \\
\hline None & 4.94 & 6.69 & 0.46 \\
\hline 1 to 3 comorbidities & -1.44 & 4.27 & 0.74 \\
\hline Complications (Ref: 1 or more) & 0.43 & 4.74 & 0.93 \\
\hline General Health Status (GHS) at baseline & 0.43 & 0.09 & $<0.001$ \\
\hline
\end{tabular}

$R^{2}=0.303 ;$ adjusted $R^{2}=0.222$

* DVT - Deep Vein Thrombosis; TPTE - Pulmonary Thromboembolism 


\section{Discussion}

Among the participants, there was a large proportion of women, with age of 60 years or older, and with atrial fibrillation. The proportion of older adults using OAT has increased around 7\% per year in Brazil(12), maybe because this age group presents comorbiditites that require use of OAT. Furthermore, the incidence of atrial fibrillation increases with age ${ }^{(13)}$, and studies have shown a large proportion of individuals 60 years or older who use OAT ${ }^{(7,13-15)}$ for that reason.

Our evaluation of HRQoL showed that there was an improvement in perceived health status and in the impact of OAT in the first six months of the therapy according to the three instruments we used: SF-36 (statistically significant improvement in all domains, except for Mental Health); GHS (statistically significant improvement); and DASS (small perceived impact of OAT). We did not find longitudinal studies of HRQOL in the literature that would allow us to compare our results in this population. Currently, we can only compare our results to crosssectional studies conducted in other $\operatorname{countries}^{(2,16-18)}$ and in Brazil(3). For the SF-36, Social Aspects was the domain that had the highest scores at baseline and six-month follow-up. Similar results were observed in a study in Brazil $^{(3)}$ and in international studies ${ }^{(7,14)}$. Other studies presented higher scores in other domains, such as Mental Health $^{(18)}$ and Emotional Aspects(16); however, in general, the participants of those studies were in different phases of the treatment with OAT. In our study, the domain with the worst score was Physical Aspects at baseline and Vitality at six-month follow-up. In contrast, other studies showed the following domains as the most compromised by OAT: Vitality ${ }^{(18)}$, Pain ${ }^{(16)}$, General Health (17), and Physical Aspects(2-3). In our study, at six-month follow-up, participants presented higher scores for all SF36 domains than two of the reviewed studies $^{(2-3)}$, which evaluated individuals with longer duration of therapy (four and seven years, respectively). The only domain in our study that did not show a statistically significant change between baseline and six-month follow-up was Mental Health (scores of 72 and 74, respectively). In other studies, those values varied from 61 to $76^{(2,3,16,18)}$.

Results from perceived general health status (GHS) showed improvement from baseline to six-month followup (mean change of 9 points, $\mathrm{p}<0.001$ ), indicating that the participants, on average, perceived their health as better after starting OAT.

Regarding quality of life related to OAT, the results from the instrument DASS showed that the perceived impact of OAT was small. Since DASS is a relatively new instrument, publications using it are mostly of methodological nature, focusing on the psychometric properties of the instrument ${ }^{(2,11)}$. On those studies, the mean DASS was 54 and 58, which are higher values than the values in our study, indicating that our participants perceived a better quality of life related to OAT (lower scores represent higher satisfaction with OAT, less limitation, less hassle and burden, and less psychological impact).

In our study, individuals with deep vein thrombosis or pulmonary thromboembolism reported lower scores in HRQoL measures than individuals with mechanical valve prosthesis. We could not find information in the literature that could explain that difference. One possible explanation is the presence of pain among individuals with deep vein thrombosis or pulmonary thromboembolism. However, persons with mechanical valve prosthesis could also experience pain due to the surgical incision. It is possible that this latter group had time to prepare for the procedure (which is elective), and consequently, prepared for the OAT use. In contrast, the group with deep vein thrombosis or pulmonary thromboembolism had an acute event, which could have surprised them with its risk of imminent death, followed by the necessity of OAT and its demands for health care.

In the multiple linear regressions, the models explained $32 \%$ of the variance of DASS and $30 \%$ of the variance of GHS. Despite their clinical importance, the explanatory variables explained little of the variance of the response variables. We expected that the models would explain more of the variance, given that the $83 \%$ of the participants presented chronic conditions other than the reason for OAT and which also demand care, possibly making the participants to accept the implications that come with the treatment by OAT, and bringing less negative impact to their lives. The same reasoning can be used for number of medications used. For a person who already has the habit of taking daily medication for other chronic conditions, to add one more medication in the daily list might cause a lesser impact in their routine than the impact in the routine of a person who has to create the habit of taking the medication at the prescribed dose and times. A possible negative impact of prescribing OAT to a person who already takes other medications is the cost for the person and the family, which could interfere in the adherence to the treatment. However, among the participants of our study, it seems that cost was not the most important factor and it did not seem 
to interfere negatively in their HRQoL. One explanation is that most participants had enough income and/or were helped by their families to acquire the medication. This fact was collected empirically by one of the authors during the interviews. Another study focusing on the perception of the OAT impact in the person's life, showed that many people abandon their old daily routines to adapt to the demands of OAT, which can bring some negative impact to their HRQoL, especially during the first few months of the treatment(1). However, despite the changes in routine required by OAT, there are individuals who report a positive impact in their lives, either because they feel protected from thromboembolic events prevented by OAT, or because the addition of OAT did not change their routines as they already used medication that required care and dedication to be adherent to it. We think that the latter occurred in our study, given the large number with other chronic conditions.

It is possible that there were influences from other factors in our study that could lead to some distortion in self-reporting, such as social desirability, which is the tendency that an individual has to answer question in a socially approved manner, in order to preserve his/ her self-image, to present him/herself in a favorable light, or to avoid negative consequences, such as reprehension ${ }^{(19)}$.

We believe that our results can help to direct planning for health care of persons using OAT, in issues related to reasons for prescription of OAT, changes in daily routine generated by OAT, and re-organization of health care to attend those demands. This study was important because it characterized the population being followed in our healthcare system as well as because it pointed to directions that need to be further investigated given the heterogeneity of the population and their response to the OAT.

One of the limitations of this study was the sample size, which was of moderate size but might not have been sufficient to study such a heterogeneous population. The data collection was done in two times only, which might not have been sufficient to describe the individual's trajectory during the period of adaption to OAT. In addition, the time between OAT initiation and the first interview, varied somewhat (within two months). Finally, the scarcity of options of valid and reliable instruments to measure HRQoL related to OAT, allowed us too few choices and at this point, there is not enough evidence that the measures we used are the best ones for the Brazilian population.

\section{Conclusions}

OAT can generate a negative impact in the lives of its users, given the routine necessary to maintain the treatment. This study contributed to the literature with the clinical evolution of OAT users, showing that it caused a positive impact in the individuals' lives at the end of six months of OAT. Future studies with larger sample sizes and longer follow-up periods are needed to increase our understanding of the oral anticoagulation therapy in the HRQoL of its users.

\section{References}

1. Prins MH, Marrel A, Carita P, Anderson D, Bousser MG, $\mathrm{Crijs} \mathrm{H}$, et al. Multinational development of a questionnaire assessing patient satisfaction with anticoagulant treatment: the "Perception of Anticoagulant Treatment Questionnaire" (PACT-QC). Health Qual Life Outcomes. [periódico na Internet]; 2009; [acesso 23 maio 2012]; 7(9):1-13. Disponível em: http://www.hqlo.com/ content/7/1/9

2. Samsa G, Matchar DB, Dolor RJ, Wiklund I, Hedner $E$, Wygant $G$, et al. A new instrument for measuring anticoagulation-related quality of life: development and preliminary validation. Health Qual Life Outcomes. 2004;6(2):22-33.

3. Corbi ISA, Dantas RAS, Pelegrino FM, Carvalho ARS. Health related quality of life of patients undergoing oral anticoagulation therapy. Rev. Latino-Am. Enfermagem. July-Aug 2011;19:865-73.

4. Fayers PM, Machin D. Quality of life - the assessment, analysis, and interpretation of patient-reported outcomes. 2nd ed. Chichester: England John Wiley; 2007. p. 3-30.

5. Avila CW, Aliti GB, Feijo MKF, Rabelo ER. Pharmacological adherence to oral anticoagulant and factors that influence the international normalized ratio stability. Rev. Latino-Am. Enfermagem [online]. Feb 2011;19(1):18-25.

6. Rocha HT, Rabelo ER, Aliti G, Souza EN. Knowledge of Patients with Mechanical Valve Prostheses Concerning Chronic Oral Anticoagulant Therapy. Rev. Latino-Am. Enfermagem; Aug 2010;18(4):696-702.

7. Platt AB, Localio R, Brensinger CM, Crues DG, Christie JD, Gross R, et al. Risk factors for nonadherence to warfarin: results from the IN-RANGE study. Pharmacoepidemiol Drug Safety. 2008;17:853-60.

8. Ware JE, Sherbourne CD. The MOS 36-item shortform health survey (SF-36). I. Conceptual framework and item selection. Medical Care. 1992;30(6):473-83. 
9. Ciconelli RM, Ferraz MB, Santos W, Meinão I, Quaresma MR. Tradução para língua portuguesa e validação do questionário genérico de avaliação de qualidade de vida SF-36. Rev Bras Reumatol. 1999;39(3):143-50.

10. Harrison MJ, Boonen A, Tugwell, Symmons DPM. Same question, different answers: a comparison of global health assessments using visual analogue scales. Qual Life Res. 2009;18:1285-92.

11. Pelegrino FM, Dantas, RAS, Corbi IS, Carvalho, ARS, Schmidt A, Pazin Filho A. Cross-cultural adaptation and psychometric properties of the Brazilian-Portuguese version of the Duke Anticoagulation Satisfaction Scale. J Clin Nurs. 2012;21(17-18):2509-17.

12. Gage BF, Fihn SD, White RH. Management and dosing of warfarin therapy. Am J Med. 2000;109(15):481-8.

13. Siebenhofer A, Rakovac I, Kleespies C, Piso B, Didjurgeit $U$. Self-management of oral anticoagulation in the elderly: rationale, design, baselines and oral anticoagulation control after one year of follow-up. Thromb Haemost. 2007;97:408-16.

14. Barcellona D, Contu P, Sorano GG, Pengo V, Marongiu F. The management of oral anticoagulant therapy: the patient's point of view. Thromb Haemost. 2000;83(1):49-53.

15. Tang EOYL, Lai CSM, Lee KKC, Wong RSM, Cheng G, Chan TYK. Relationship between patients' warfarin knowledge and anticoagulation control. Ann Pharmacother. 2003;37:34-9.

16. Casais $P$, Merschengieser SS, Sanches-Luceros A, Lazzari MA. Patients perceptions' regarding oral anticoagulation therapy and its effect on quality of life. Current Med Res Opinion. 2005;21(7):1085-90.

17. Hedner E, Carlsson J, Kulich KR, Stigendal L, Ingelgard A, Wiklund I. An instrument for measuring health-related quality of life in patients with deep venous thrombosis (DVT): development and validation of deep venous thrombosis quality of life (DVTQOF) questionnaire. Health Qual Life Outcomes. 2004;2(30):1-8.

18. Lancaster TR, Singer DE, Sheehan MA, Oertel LB, Maraventano SW, Hughes RA, et al. The impact of longterm warfarin therapy on quality of life - evidence from a randomized trial. Arch Intern Med. 1991;151:1944-9. 19. Gagné C, Godin G. Improving self-report measures of non-adherence to HIV medications. Psychol Health. $2005 ; 20(6): 803-16$. 